\title{
TRANSCRIPTOME AND PROTEOMICS INTERACTION REVEALS LOW SEED GERMINATION OF CYCLOBALNOPSIS GILVA TO SAVE FOREST ECOLOGY
}

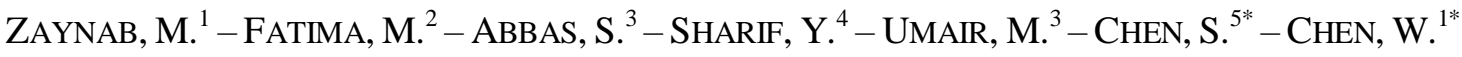 \\ ${ }^{I}$ College of Life Sciences, Fujian Agriculture and Forestry University, 350002 Fuzhou, P. R. \\ China \\ ${ }^{2}$ College of Crop Science, Fujian Agriculture and Forestry University, 350002 Fuzhou, P. R. \\ China \\ ${ }^{3}$ Department of Biochemistry, Quaid-i-Azam University, Islamabad, Pakistan \\ ${ }^{4}$ College of Plant Protection, Fujian Agriculture and Forestry University, 350002 Fuzhou, P. R. \\ China \\ ${ }^{5}$ College of Forestry, Fujian Agriculture and Forestry University, 350002 Fuzhou, P. R. China \\ *Corresponding authors \\ e-mail:weichen@fafu.edu.cn,weichen909@163.com (Wei Chen) \\ e-mail: fjcsp@126.com; phone: +86-591-8378-9367; fax: +86-591-8378-9352 (Shipin Chen)
}

(Received $13^{\text {th }}$ Jun 2018; accepted $1^{\text {st }}$ Aug 2018)

\begin{abstract}
Tree species display wide range of heterogeneity in their size, type, dormancy and growth of seed. Data about variation in germination under natural conditions and tree growth in connection with mentioned attributes is of immense value to understand tree distribution and forest stand management. Studies dealing with tree seed germination can enable successful nursery operations and healthy seedling production. This may also increase the seedlings' establishment in the forest restoration activities on destructed sites through native plant species. Successful germination is not only critical for plantlet establishment but also necessary for crop yield. As seed detaches from mother plant it desiccates continuously and selects suitable environment for germination activity. To understand the low germination rate in Cyclobalnopsis gilva molecular aspects of germination has been elucidated well with the integrated studies of proteomic, transcriptomic molecular biology. In this review, common and different aspects of seed germination including metabolic activation, transcription and translation regulation, have been discussed. This review will help to understand the transcriptomic and proteomic interaction of $C$. gilva which will be helpful to save the forest ecology and solve the problem of woody plants with low germination rate all over the world.
\end{abstract}

Keywords: environment, woody plants, forest, metabolic activation, transcription, translation

\section{Introduction}

Seed germination comprises of three interlinked processes, such as (I) rapid water uptake, (II) plateau phase and (III) post-germination. Phase (I) starts with the water absorption which helps in the breakdown of starch, proteins, and lipids along with the continuity of glycolytic and oxidative pentose phosphate pathways (Howell et al., 2007; Macovei et al., 2011). Phase II involves mitochondrial synthesis (Howell et al., 2007) and translation of stored mRNA (Dinkova et al., 2011; Fig. 1). Phase III follows the elongation of embryonic axes leading to radicle growth. Previous research studies have explained seed germination with considerable progress from more than two decades. However, there are many small circles of seed germination, which demands more 
exploration for the proper understanding of mutual linkages between various pathways (He and Yang, 2013).

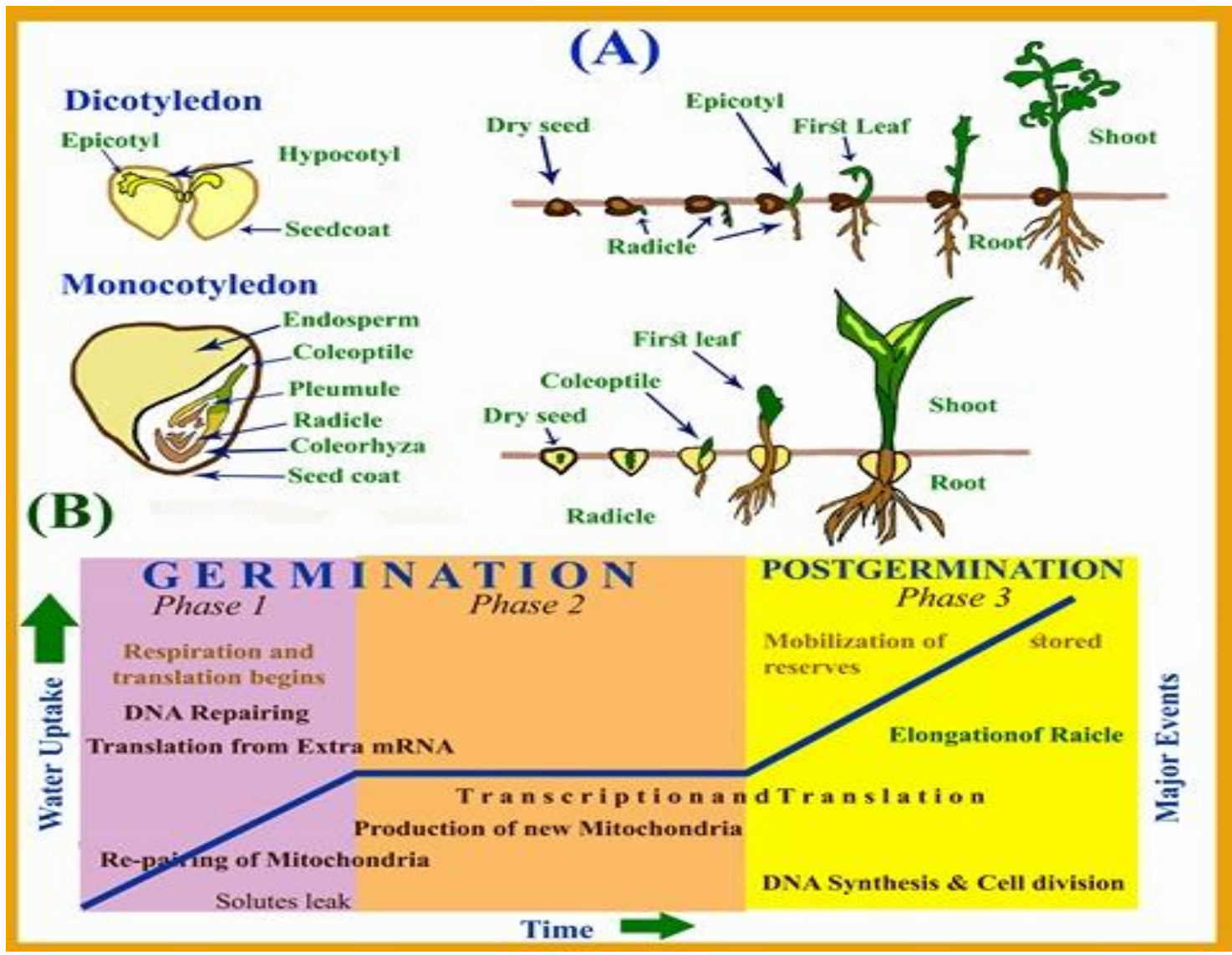

Figure 1. Following imbibition, seed germination could be divided into three major steps. First of all, rapid uptake of water occurs which results in biosynthesis of mRNA. Second step includes more important activities which involves reactivation of metabolism, mobilization of stored reserves, loosening of cell wall, repair of cell structure and coleoptile enlargement. Again rapid uptake of water occurs during the last step, upon which respiration and TCA recovers, cell multiplication, radical emergence and seedling establishment initiates

In Arabidopsis, barley and rice more than ten thousand stored mRNA and transcripts have been identified and several studies confirmed that mRNA are stored during seed maturation (Rajjou et al., 2004; Nakabayashi et al., 2005; Kimura and Nambara, 2010; Okamoto et al., 2010; Radchuk et al., 2007). Until now, the confirmed transcriptomes from whole dry seeds have presented the diverse type of transcripts according to their genetic and physiological parts like the embryo and endosperm (Le et al., 2010). Furthermore, the transcriptional theory was genuinely authenticated by Kimura and Nambara (2010). Seed germination depends upon the variation in physio-chemistry of different parts of seeds i.e. embryo, endosperm seed coat and interaction among them (Nonogaki et al., 2000). Embryo is a vital part of the seed, as it contains genetic information required for triggering the seed germination process (Sheoran et al., 2005). There are several enzymes involved in metabolic pathways during seed germination and that stored during seed maturation (www.seed-proteome.com) (Rajjou et al., 2004; Fujino et al., 2008; Gallardo et al., 2001). Okamtao (2010) reported that during 
imbibition transcriptome profile in germinating seed changes and even these changes are tissue specific. During early germination, transcripts are noticed to share similar or common but highly abundant cis-acting elements in their respective gene promotor followed by high expression pattern (Marcus and Feeley, 1964; Dure and Waters, 1965; Comai and Harada, 1990). Degradation of stored mRNA is associated with a change in expression of a gene (Comai and Harada, 1990; Nakabayashi et al., 2005; Howell et al., 2009; Preston and Hileman, 2009). The mechanisms involved in seed germination, numerous broad-spectrum omics studies have been conducted across the globe, involving transcriptomic approaches (Holdsworth et al., 2008; Sghaier-Hammami et al., 2009a, b). Productivity and survival of woody plants is continuously affected by multiple stresses (Pinheiro et al., 2014). Plants growth is negatively affected by surrounding biotic and abiotic stress agents that cause physical and biological dysfunctions and plants differ in their ability to overcome these stresses. Aside from the huge proteomics data available for woody plants, limited information is available on seed germination. Until now, Fagus sylvatica is among the limited plants for which attempts has been made to know the proteomic changes associated with seed germination (Pawlowski, 2007), similarly P. dactylifera (Sghaier-Hammami et al., 2009a, b), J. curcas (Yang et al., 2009) and P. campanulata (Lee et al., 2006) are some other examples. Depending upon seed dormancy woody plants have four categories (Gendreau and Corbineau, 2009) that are physical, mechanical, morphological and embryo dormancy. Fukumoto and Kajimura (2001) reported the poor regeneration of Cyclobalnopsis sp is due to insect damage of seeds and deer grazing of regenerating seedlings which are threatening the successful regeneration of Cyclobalnopsis sp. Transcriptome and proteomic interaction of woody plants during the seed germination studies has been ignored till now. Cyclobalnopsis gilva a woody plant has low germination rate as compared to other plants (Meiqing et al., 2012). It belongs to Fagaceae family and because of its hardness it is used in the furniture industry. (Zaynab et al., 2017). It is native in the southeastern part of China (Fig. 2). Among evergreen broad leaves, Cyclobalanopsis is one of an abundantly found woody tree which is a good biological filter that reduces environmental pollution (Deng et al., 2014). Being efficient natural cleaners, trees can help to overcome environmental pollution (Seth et al., 2003). Leaves with hairy, spiny and waxy surface can easily absorb gaseous form of pollutants while particle forms of pollutants can be trapped by twigs, branches and tree stems. Trees reduce carbon oxides, disintegrate waste materials and fix nitrogen in atmosphere. Trees act as pollution sinks and metabolize heavy metals and absorb toxic gases from the surrounding environment (Yang et al., 2017). There are no studies reported transcriptome and proteome changes analysis during seed germination of $C$. gilva. The basic purpose of this study/review is to describe transcript and protein change during the complex mechanisms of seed germination of C. gilva.

\section{Transcription and translation activation}

Gene expression changes dramatically at proteomic as well as transcriptomics level as seed imbibes water (Fig. 3) (Holdsworth, 2008). Weitbrech et al. (2011) reported that these alterations in gene expression are related to germination. It is considered that transcription is not going on in fully ripened seed, but mRNAs which are essential for germination have already been stored (Howell, 2009). Large number of mRNA species are present in fully ripen seed. Over 12000 mRNA have been found in mature seeds of 
Arabidopsis. He et al. (2011) in rice embryo, about 17000 mRNA have been found (Howell, 2009). In rice and Arabidopsis $\alpha$-amanitin, a transcription inhibitor has found to delay germination but not totally block it (Rajjou, 2004). It looks that transcription inhibitors have greater role to play in seedling establishment than in germination (He et al., 2011). These results suggest that factors assuring the germination speed are synthesized in de novo transcription. High increase in transcription occur in rice embryo after 3 to $12 \mathrm{~h}$ of water absorption which results in increased secondary metabolites production that are involved in cell wall, amino acids, carbohydrates metabolism (Howell, 2009). Rice and Arabidopsis germination was diminished in the presence of translation inhibitors which showed that instead of transcription, translation is prerequisite of germination (Rajjou, 2004). New protein synthesis in Arabidopsis starts $8 \mathrm{~h}$ after imbibition. That is why it is proposed that stored mRNAs are utilized for this protein synthesis. For metabolites activation and mobilization of reserves translation of stored mRNAs was important in both rice and Arabidopsis seeds (Rajjou, 2012, 2006). In maize seeds in vitro incubation experiments demonstrated that eIF(iso) $4 \mathrm{E}$ is required for translation of stored mRNAs (Dinkova et al., 2011). Arabidopsis double mutant i4g1/i4g2 knocked out for eIFiso4G1 and eIFiso4G2 (responsible for stored mRNA translation) showed diminished germination rate and long seed viability (Lellis, 2010). Form this experiment it was clear that cereal seeds and Arabidopsis possess similar mode of translation for stored mRNA.

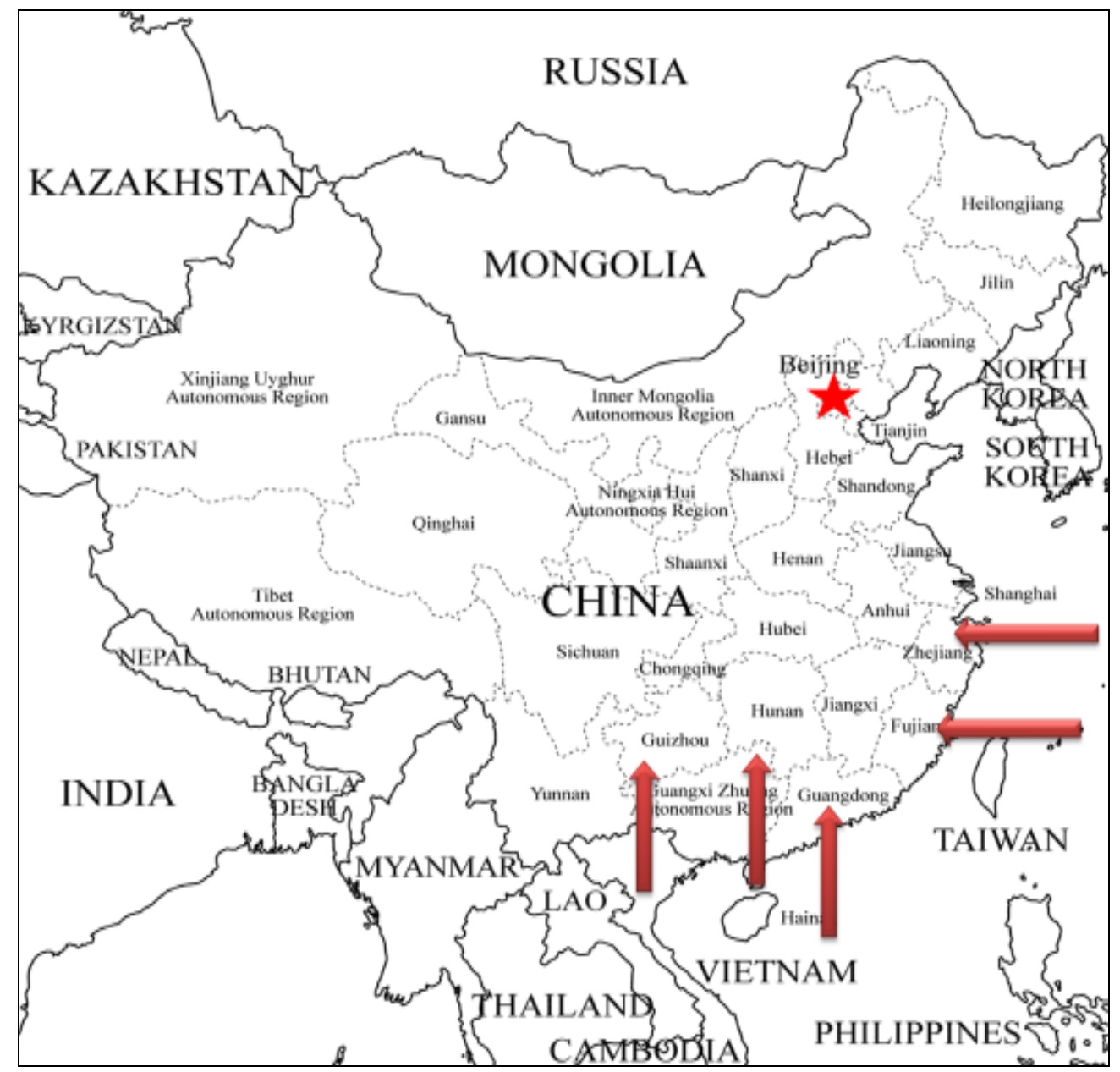

Figure 2. Presence of C. gilva in the southeastern ecological region of China 


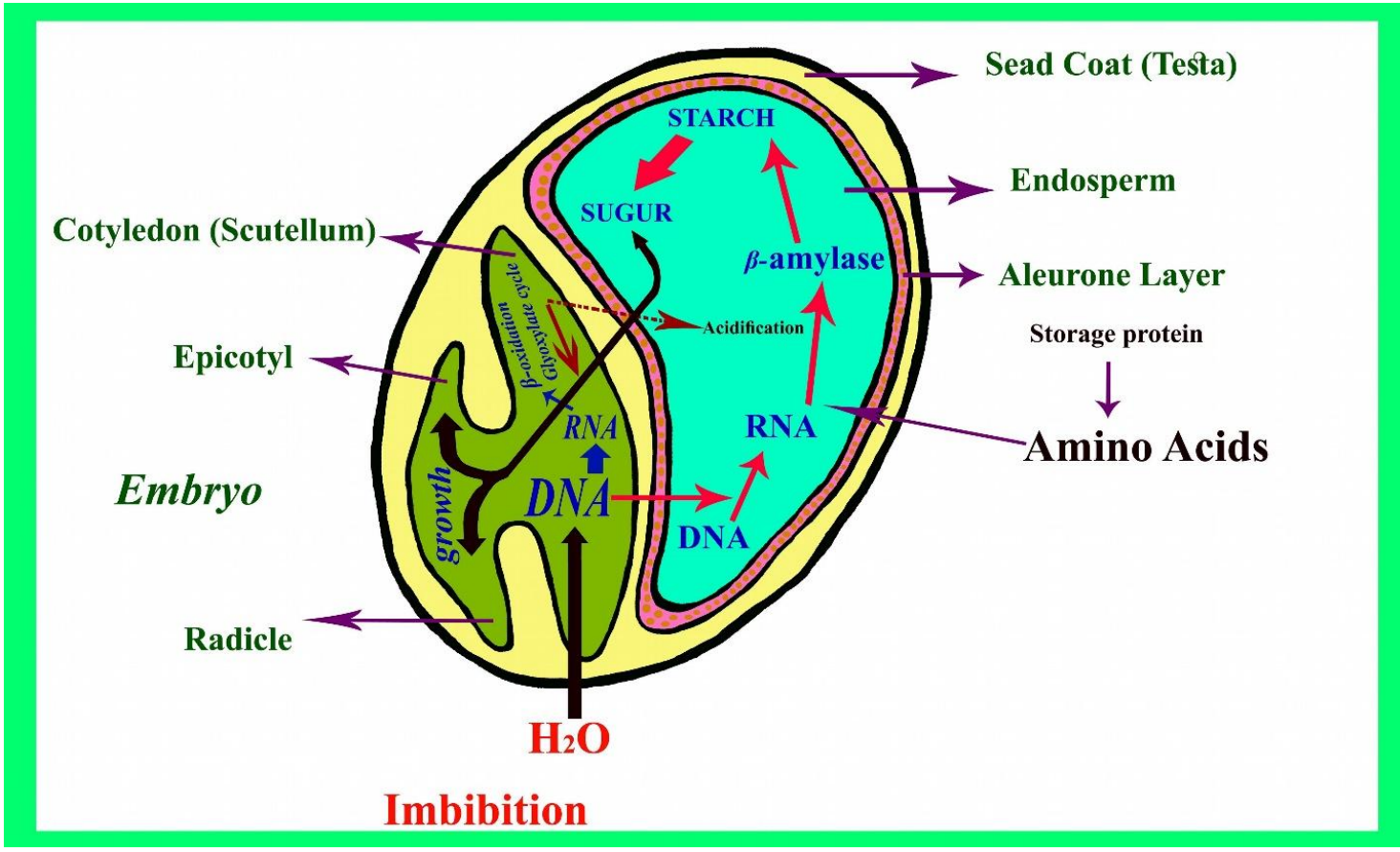

Figure 3. Molecular processes occurring in embryo and endosperm during C. gilva seed germination

\section{Role of translation in seed germination}

Previous observation inferred that upon imbibition radicle protrude out of seed coat in Arabidopsis seed in the presence a specific, potential inhibitor of DNA-dependent RNA polymerase " $\alpha$-amanitin", this showed that seed germination is not limited to de novo transcription (Rajjou, 2004). To speed up the germination vigor, de novo synthesis of transcripts encoding proteins and enzymes involved in GAs biosynthesis and involved in germination sensitivity to this hormone is important because germination uniformity and speed is strongly affected under absence of these transcripts. In contrast, under the presence of translation inhibitor "cycloheximide" Arabidopsis germination was totally blocked (Rajjou, 2001). These results highlight the importance of protein synthesis especially from the stored RNA templates in seed for the completion of germination. As seed store RNA and proteins during maturation on source plant, role of these stored elements is clear from these results and for Arabidopsis seed germination potential is planned during seed maturation. For germination, other studies have also identified the core role of translation. During germination of mature seeds high contribution of stored mRNA has been confirmed by transcriptome analysis (Nakabayashi et al., 2005). The study conducted by Nakabayashi et al. (2005) elaborated the importance of protein synthesis during early germination stages, as $2 \%$ to $3 \%$ genes showed upregulation while evidence was also provided by ribosomal proteins coding genes and translation initiation and elongation factors.

Recent analysis of sugarbeat (Beta vulgaris L.) seed proteome identified 758 proteins reconstructing and inferring their detailed metabolic status (Catusse et al., 2008). Seeds are prepared for germination mainly during maturation on plan as indicated by sugar beet seeds, which are prepared to mobilize their reserves including starch, proteins, phytate and triglycerides during germination as occur in Arabidopsis and they also 
identified proteins not mentioned in seeds. Promisingly, data highlight that sugar beet seeds have opportunity to initiate translation either by using cap-independent mechanism or conventional way of cap-dependent mechanism. It is clear that during some events of cell life like during stress conditions or viral infection and mitosis, cell compromises its standard way of translation i.e. 5-end cap-recognition of mRNA while at the same time some mRNA use cap-independent mechanism of initiation as congregation initiation site for initiation factor (Baird et al., 2006). A model is suggested by these findings. In this model germinating seed has two pools of mRNA comprising of de novo synthesized mRNA and stored mRNA and during germination these pools allow their recruitment by either of two initiation pathways (Catusse et al., 2008). In maize seed, during embryonic axis elongation, stored mRNAs were likely to use cap-independent mechanism for translation initiation (Dinkova et al., 2005).

\section{Comparison of the seed transcriptome and proteome}

Comparison of several proteome and transcriptome studies carried out in the same environmental conditions and sampling points, showed little correlation between functional gene classes at proteomics and transcriptomics level (Gallardo et al., 2002; Ogawa et al., 2003; Chibani et al., 2006; Carrera et al., 2008). Germination vigor can possibly change the abundance of RNA present in seed for germination completion, some functions associated with establishment of seedling (translation after germination completion), for observation of changes in protein profiles, proteomic approaches are not sensitive enough. Up till now it is also vague that changes in seed dormancy status are controlled by translational or post-translational regulations (Holdsworth et al., 2008). Gene expression study is critically important to understand the molecular network involved in germination regulation as the list of genes regulated in imbibed seeds obtained through either proteomic (Chibani et al., 2006) or transcriptomic (Cadman et al., 2006) approaches showed similarities. Integration of information from proteomic and transcriptomic studies will be the key objective for further post-genomic research. Favorably, some proteomic and transcriptomic based studies under similar time essays and growth conditions are helping to integrate the information from different studies (Cadman et al., 2006; Chibani et al., 2006; Carrera et al., 2008).

Due to less germination rate of woody plants proteomic studies of seed germination are getting more importance (Zaynab et al., 2017; Canovas et al., 2004). It is difficult to examine woody plants due to laborious sample preparation and high concentrations of resins, tannins and phenolic compounds (Sebastiana et al., 2013). In a study, $P$. dactylifera L. (Date palm) proteomic studies for seed development and germination were done by Sghaier-Hammami et al. (2009) and they reported that carbohydrates, the major storage reserves are stored in early seed development which are used during initial stages of seed germination.

Comprehensive information regarding access amount of some functional protein types related to seed ripening, dormancy and germination have been provided by the proteomic analysis of germinating seeds. Many other studies have also shown the proteome changes related to dormancy and germination status (Gallardo et al., 2001, 2002; Job et al., 2005; Chibani et al., 2006; Oracz et al., 2007), regarding this information seed biology is a prominent host of plant proteomics. Proteomics is a strategy for global analysis that provides information on a multitude of processes in complex events, such as germination (Gallardo et al., 2001). Despite the increasing 
interest in plant proteomics, studies on woody plant seed germination are still very limited. To date, the only attempts to understand proteome changes during the germination of woody plants were carried out in Prunus campanulata (Lee et al., 2006), Fagus sylvatica (Pawlowski, 2007), Acer platanoides (Pawlowski, 2009), Jatropha curcas (Yang et al., 2009), Phoenix dactylifera (Sghaier-Hammami et al., 2010, 2009b) and Araucaria angustifolia (Balbuena et al., 2011). Only a limited number of reports about proteomics in woody plant seed germination have been published. Lu et al. (2016) conducted a study to determine the mechanisms involved in seed dormancy breaking of M. sieboldii to better understand the anatomical and translation bases of seed germination in this species and they reported that a small subunit of legumin precursor, ADP-glucose pyrophosphorylase and aspartic proteinase dominate the seed proteome of M. sieboldii. Such studies not only provide information regarding the protein abundance in dry stored seeds and imbibed seeds but also elaborate the post-translational modifications for proteome expression. Gallardo et al. (2001) reported the proteome changes related to imbibition germination while Chilbani et al. (2006) studied the imbibed ripened seeds. Rajjou et al. (2004) noticed that germination in alpha-amanitin treated transparent testa (tt) of mutant seeds was not blocked concluded that transcription was not important for germination. On the other hand, cycloheximide was a potential inhibitor of radicle emergence. If transcription was important for expression of genes involved in synchronization and speed of germination was answered by the $\alpha$ amanitin treatment. Seeds treated with $\alpha$-amanitin showed great germination potential, but germination rate was slow and less sensitive to GA application and the level of several key proteins for germination (malate synthase) (Eastmond et al., 2000) were very low in treated seeds. Chibani et al. (2006) reported great difference in protein profiles of after-ripened and imbibed seeds of accession CVI. In dormant seeds lack of germination was not associated with less de novo protein production because $35 \mathrm{~S}$ methionine incorporation quantification showed the same incorporation level in afterripened and dormant seeds (Carrera et al., 2008). Exogenous ABA application greatly lowered the germination potential in after-ripened imbibed seeds, but it did not alter dormancy at proteomic level (Chibani et al., 2006). 35S methionine incorporation in ABA treated after-ripened imbibed seeds were greater that non-treated and dormant seeds, this indicated that ABA treatment does not hinder RNA translation protein abundance was also high in treated seeds. Both proteomic and transcriptomic studies showed that instead of seed dormancy ABA treatment use another way of inhibiting germination. This is not surprising because physiologically ABA does not reduce germination potential but only delay it (Muller et al., 2006). It is very likely that ABA application to un-germinated seeds just like drought and salinity causes increased ABA production, these responses have already been observed in germinating seedlings (Lopez-Molina et al., 2002).

\section{Post-translational control of seed germination}

A growing number of evidence indicates that large changes in redox state of protein occur as seed germinates. In dry cereal seeds proteins are present in oxidized (S-S) form in embryo and starchy endosperm, upon imbibition these are converted into sulfhydryl (-SH) or reduced form (Buchanan and Balmer (2005)). Thioredoxin (Trx), a regulatory protein seems to play core role in redox conversion. Trx cause reduction enzymatically in the presence of NADPH and facilitates reserves mobilization during germination in 
three ways i.e. enhancing protein susceptibility and sensitivity to proteolysis by reducing them, enhancing breakdown of stored proteins and starch as it inactivates disulfide proteins inhibiting specific proteases and amylases and it activates enzymes functioning in germination (Fig. 3; Buchanam and Balmer, 2005). This issue has recently been investigated in barrel clover (Medicago truncatula) (Alkhalfoui, 2007). Role of Trx in monocotyledons and dicotyledons seed germination have been proved. It can be summarized that in dry and fully mature seeds oxidized proteome keep seed metabolically dormant, which is activated. It can be summarized that oxidized proteome in metabolically dormant seed is by redox reaction in protein bisulfide bridges in the presence of specific Trx during seed germination. Given the large number of proteins affected (more than 100) Alkhalfioui (2007), post-translational mechanism offers an efficient and simple way of controlling complex pathways critical in seed germination. It follows, that investigation of targets like post-translational modifications becomes an emerging question. As post-translational changes may become key regulators of cell activity upon imbibition, so this question is importance increasingly. Carbonylation of proteins by reactive oxygen species may be another oxidative change. In several model systems carbonylated proteins accumulation is referred to aging, but it is not for Arabidopsis where germination rate is high, and seedlings are vigorous. Results indicates that changes in protein carbonylation patterns may occur to nullify the ROS produced in germinating seeds by recovery of metabolic processes. Job et al. (2005) conducted a study in which it is suggested that carbonylation of proteins stored in seed is to facilitate the protein mobilization at time of seed germination. Jatropha and other woody plants store the metabolic reserves as starch, proteins and lipids in embryo and endosperm (Yang et al., 2009). Triacylglycerol (TAG) the major form of lipids is the storage reserve of oilseed plants. TAG is broken down by lipases to release fatty acids which are further catabolized in glyoxilate cycle and $\beta$-oxidation. Seed germination and development mechanism of woody plant $A$. angustifolia was studied by Balbuena et al. (2011). Their study showed the differential expression of proteins in germinated and mature embryos which suggests the activation of robust metabolic pathways, translation initiation and stress regulation, overall indicates active degradation metabolism.

\section{Conclusion and perspectives}

Like any other field of plant science seed biology is of importance and attracting attention of plant biologists. Previous studies have suggested complicated signalling network and gene expression regulation are involved in seed germination. Plants may share same molecular mechanisms as transcription and translational activation, phytohormone behavior, radicle protrusion etc. however different plant species possess distinct mechanisms, especially for metabolism activation and reserves mobilization. Furthermore, cross-talk among environmental factor signalling pathways and phytohormones during germination is spurious up till now. With the advent of omics era, molecular pathways underlying the germination are becoming more elaborated. For example, during germination, role of functional proteins and specific signalling components in rice and Arabidopsis have been identified by proteomic and phosphoproteomic studies. However, still much information is required to understand the germination process. Nevertheless, in future integration of newly emerging techniques including ChIP-sequencing, proteomic and transcriptomic techniques and imaging will contribute to understand the process how different signals conciliate seed 
germination. To better understand the underlying mechanisms of desiccation tolerance and intolerance, the physiological responses described require research at the metabolomic and transcriptomic levels in detail.

Acknowledgements. This work was supported by the Industry-University Cooperation Program of Science and Technology Commission Foundation of Fujian Province (Grant No. 2016N5003).

Conflict of interests: The authors declare no conflict of interest.

\section{REFERENCES}

[1] Alkhalfioui, F., Renard, M., Vensel, W. H., Wong, J., Tanaka, C. K., Hurkman, W. J., Montrichard, F. (2007): Thioredoxin-linked proteins are reduced during germination of Medicago truncatula seeds. - Plant Physiology 144(3): 1559-1579. http://doi.org/10.1104/pp.107.098103.

[2] Baird, S. D., Turcotte, M., Korneluk, R. G., Holcik, M. (2006): Searching for IRES. RNA 12(10): 1755-1785.

[3] Buchanan, B. B., Balmer, Y. (2005): Redox regulation: a broadening horizon. - Annu Rev Plant Biol. 56: 187-220.

[4] Cadman, C. S., Toorop, P. E., Hilhorst, H. W., Finch-Savage, W. E. (2006): Gene expression profiles of Arabidopsis Cvi seeds during dormancy cycling indicate a common underlying dormancy control mechanism. - Plant J. 46(5): 805-22.

[5] Carrera, E., Holman, T., Medhurst, A., Dietrich, D., Footitt, S., Theodoulou, F. L., Holdsworth, M. J. (2008): Seed after-ripening is a discrete developmental pathway associated with specific gene networks in Arabidopsis. - The Plant Journal 53(2): 214224.

[6] Catusse, J., Job, C., Job, D. (2008): Transcriptome- and proteome-wide analyses of seed germination. - C R Biol. 331(10): 815-822.

[7] Chibani, K., Ali-Rachedi, S., Job, C., Job, D., Jullien, M., Grappin, P. (2006): Proteomic Analysis of Seed Dormancy in Arabidopsis. - Plant Physiology 142(4): 1493-1510. http://doi.org/10.1104/pp.106.087452.

[8] Comai, L., Harada, J. J. (1990): Transcriptional activities in dry seed nuclei indicate the timing of the transition from embryogeny to germination. - Proc Natl Acad Sci USA 87: 2671-2674.

[9] Corbineau, F., Xia, Q., Bailly, C., El-Maarouf-Bouteau, H. (2014): Ethylene, a key factor in the regulation of seed dormancy. - Front. Plant Sci 5: 1-13.

[10] Deng, M., Hipp, A., Song, Y. G., Li, Q. S., Coombes, A., Cotto, A. (2014): Leaf epidermal features of Quercus subgenus Cyclobalanopsis (Fagaceae) and their systematic significance. - Bot J Linean Soc. 176(2): 224-259.

[11] Dinkova, T. D., Márquez-Velázquez, N. A., Aguilar, R., Lázaro-Mixteco, P. E. (2011): Tight translational control by the initiation factors eIF4E and eIF(iso)4E is required for maize seed germination. - Seed Sci. Res. 21(2): 85-93.

[12] Dure, L., Waters, L. (1965): Long-lived messenger RNA: evidence from cotton seed germination. - Science 147: 410-412.

[13] Eastmond, P. J., Germain, V., Lange, P. R., Bryce, J. H., Smith, S. M., Graham, I. A. (2000): Postgerminative growth and lipid catabolism in oilseeds lacking the glyoxylate cycle. - Proc. Natl. Acad. Sci. U. S. A. 97: 5669-5674.

[14] Fujino, K., Sekiguchi, H., Matsuda, Y., Sugimoto, K., Ono, K., Yano, M. (2008): Molecular identification of a major quantitative trait locus, qLTG3-1: controlling lowtemperature germinability in rice. - Proc Natl Acad Sci USA 105: 12623-12628. 
[15] Fukumoto, H., Kajimura, H. (2001): Guild structures of seed insects in relation to acorn development in two oak species. - Ecological Research 16(1): 145-155.

[16] Gallardo, K., Job, C., Groot, S. P., Puype, M., Demol, H., Vandekerckhove, J., Job, D. (2001): Proteomic analysis of arabidopsis seed germination and priming. - Plant Physiol. 126(2): 835-848.

[17] Gallardo, K., Job, C., Groot, S. P. C., Puype, M., Demol, H., Vandekerckhove, J., Job, D. (2002): Proteomics of Arabidopsis Seed Germination. A Comparative Study of WildType and Gibberellin-Deficient Seeds. - Plant Physiol. 129(2): 823-837.

[18] Gendreau, E., Corbineau, F. (2009): Physiological aspects of seed dormancy in woody ornamental plants. - Propagation of Ornamental Plants. 9(3): 151-158.

[19] Hauvermale, A. L., Ariizumi, T., Steber, C. M. (2012): Gibberellin signaling: a theme and variations on DELLA repression. - Plant Physiol 160: 83-92.

[20] He, D., Yang, P. (2013): Proteomics of rice seed germination. - Front Plant Sci 4: 1-9.

[21] He, D., Han, C., Yao, J., Shen, S., Yang, P. (2011): Constructing the metabolic and regulatory pathways in germinating rice seeds through proteomic approach. - Proteomics 11: 2693-2713.

[22] Holdsworth, M. J., Bentsink, L., Soppe, W. J. (2008): Molecular networks regulating Arabidopsis seed maturation, after-ripening, dormancy, and germination. - New Phytol 179: 33-54.

[23] Howell, K. A., Cheng, K., Murcha, M., Jenkin, L. E., Millar, A. H. Whelan, J. (2007): Oxygen initiation of respiration and mitochondrial biogenesis in rice. - J Biol Chem 282: 15619-15631.

[24] Howell, K. A., Narsai, R., Carroll, A., Ivanova, A., Lohse, M., Usadel, B., Millar, A. H., Whelan, J. (2009): Mapping metabolic and transcript temporal switches during germination in rice highlights specific transcription factors and the role of RNA instability in the germination process. - Plant Physiol 149: 961-980.

[25] Job, C., Rajjou, L., Lovigny, Y., Belghazi, M., Job, D. (2005): Patterns of protein oxidation in Arabidopsis seeds and during germination. Plant Physiol. 138: 790-802.

[26] Kimura, M., Nambara, E. (2010): Stored and neosynthesized mRNA in Arabidopsis seeds: effects of cycloheximide and controlled deterioration treatment on the resumption of transcription during imbibition. - Plant Mol Biol 73: 119-129.

[27] Le, B. H., Cheng, C., Bui, A. Q., Wagmaister, J. A., Henry, K. F., Pelletier, J., Kwong, L., Belmonte, M., Kirkbride, R., Horvath, S. (2010): Global analysis of gene activity during Arabidopsis seed development and identification of seed-specific transcription factors. -Proc Natl Acad Sci USA 107: 8063-8070.

[28] Lee, C. S., Chien, C. T., Lin, C. H., Chiu, Y. Y., Yang, Y. S. (2006): Protein changes between dormant and dormancy-broken seeds of Prunus campanulata - Maxim. Proteomics. 6(14): 4147-4154.

[29] Lellis, A. D., Allen, M. L., Aertker, A. W., Tran, J. K., Hillis, D. M., Harbin, C. R., Browning, K. S. (2010): Deletion of the eIFiso4G subunit of the Arabidopsis eIFiso4F translation initiation complex impairs health and viability. - Plant Molecular Biology 74(3): 249-263.

[30] Lopez-Molina, L., Mongrand, S., McLachlin, D. T., Chait, B. T., Chua, N. H. (2002): $\mathrm{ABI} 5$ acts downstream of $\mathrm{ABI} 3$ to execute an $\mathrm{ABA}$-dependent growth arrest during germination. - Plant J 2: 317-328.

[31] Macovei, A., Balestrazzi, A., Confalonieri, M., Faé, M., Carbonera, D. (2011): New insights on the barrel medic MtOGG1 and MtFPG functions in relation to oxidative stress response in planta and during seed imbibition. - Plant Physiol Biochem 49: 1040-1050.

[32] Marcus, A., Feeley, J. (1964): Activation of protein synthesis in the imbibition phase of seed germination. - Proc Nat AcadSci USA 51: 1075-1079.

[33] Meiqing, J., Zhihui, L., Mohua, Y., Lijun, W., Qian, S. (2012): The study on seed quality and germination characteristics of cyclobalanopsis gilva (Bl.) Oerst. - Chin Agric Sci Bull. 34: 008-009. 
[34] Müller, K., Tintelnot, S., Leubner-Metzger, G. (2006): Endosperm-limited Brassicaceae seed germination: abscisic acid inhibits embryo-induced endosperm weakening of Lepidium sativum (cress) and endosperm rupture of cress and Arabidopsis thaliana. Plant Cell Physiol. 47(7): 864-77.

[35] Nakabayashi, K., Okamoto, M., Koshiba, T., Kamiya, Y., Nambara, E. (2005): Genome-wide profiling of stored mRNA in Arabidopsis thaliana seed germination: epigenetic and genetic regulation of transcription in seed. - Plant J 41: 697-709.

[36] Nonogaki, H., Gee, O. H., Bradford, K. J. (2000): A germination-specific endo- $\beta$ mannanase gene is expressed in the micropylar endosperm cap of tomato seeds. - Plant Physiol123: 1235-1246.

[37] Ogawa, M., Hanada, A., Yamauchi, Y., Kuwahara, A., Kamiya, Y., Yamaguchi, S. (2003): Gibberellin Biosynthesis and Response during Arabidopsis Seed Germination. The Plant Cell 15(7): 1591-1604.

[38] Okamoto, M., Tatematsu, K., Matsui, A., Morosawa, T., Ishida, J., Tanaka, M., Endo, T. A., Mochizuki, Y., Toyoda, T., Kamiya, Y. (2010): Genome-wide analysis of endogenous abscisic acid-mediated transcription in dry and imbibed seeds of Arabidopsis using tiling arrays. - Plant J 62: 39-51.

[39] Oracz, K., El-Maarouf Bouteau, H., Farrant, J. M., Cooper, K., Belghazi, M., Job, C., Job, D., Corbineau, F., Bailly, C. (2007): ROS production and protein oxidation as a novel mechanism for seed dormancy alleviation. - Plant J. 50(3): 452-465.

[40] Pawłowski, T. A. (2007): Proteomics of European beech (Fagus sylvatica L.) seed dormancy breaking: influence of abscisic and gibberellic acids. - Proteomics 7(13): 224657.

[41] Pawłowski, T. A. (2009): Proteome analysis of Norway maple (Acer platanoides L.) seeds dormancy breaking and germination: influence of abscisic and gibberellic acids. BMC Plant Biol. 9: 48.

[42] Pinheiro, H. A., DaMatta, F. M., Chaves, A. R. M., Loureiro, M. E., Ducatti, C. (2005): Drought Tolerance is Associated with Rooting Depth and Stomatal Control of Water Use in Clones of Coffea canephora. - Annals of Botany 96(1): 101-108.

[43] Preston, J. C., Hileman, L. C. (2009): Developmental genetics of floral symmetry evolution. - Trends Plant Sci 14: 147-154.

[44] Radchuk, R., Radchuk, V., Götz, K. P., Weichert, H., Richter, A., Emery, R. J., Weschke, W., Weber, H. (2007): Ectopic expression of phosphoenolpyruvate carboxylase in Vicianarbonensisseeds: effects of improved nutrient status on seed maturation and transcriptional regulatory networks. - Plant J 51: 819-839.

[45] Rajjou, L., Gallardo, K., Debeaujon, I., Vandekerckhove, J., Job, C., Job, D. (2004): The effect of $\alpha$-amanitin on the Arabidopsis seed proteome highlights the distinct roles of stored and neosynthesized mRNAs during germination. - Plant Physiol. 4: 1598-1613.

[46] Rajjou, L. Duval, M. Gallardo, K. Catusse, J., Bally, J., Job, C., Job, D. (2012): Seed Germination and Vigor. - Annu Rev Plant Biol. 63: 507-533.

[47] Sebastiana, M., Figueiredo, A., Monteiro, F., Martins, J., Franco, C., Coelho, A. V., Vaz, F., Simões, T., Penque, D., Pais, M. S., Ferreira, S. (2013): A possible approach for gelbased proteomic studies in recalcitrant woody plants. - Springerplus. 2(1): 210.

[48] Seth, A., Rojas, M., Liebmann, B., Qian, J. H. (2003): Daily rainfall analysis for South America from a regional climate model and station observations. - Geophys Res Lett. 31(7): L07213.

[49] Sghaier-Hammami, B., Valledor, L., Drira, N., Jorrin-Novo, J. V. (2009a): Proteomic analysis of the development and germination of date palm (Phoenix dactylifera L.) zygotic embryos. - Proteomics 9: 2543-2554.

[50] Sghaier-Hammami, B., Drira, N., Jorrín-Novo, J. V. (2009b): Comparative 2-DE proteomic analysis of date palm (Phoenix dactylifera L.) somatic and zygotic embryos. J Prot 73: 161-177. 
[51] Sheoran, I. S., Olson, D. J., Ross, A. R., Sawhney, V. K. (2005): Proteome analysis of embryo and endosperm from germinating tomato seeds. - Proteomics 5: 3752-3764.

[52] Weitbrecht, K., Müller, K., Leubner-Metzger, G. (2011): First off the mark: early seed germination. - J Exp Bot 62: 3289-3309.

[53] Yang, J., Ji, X., Deane, D. C., Wu, L., Chen, S. (2017): Spatiotemporal Distribution and Driving Factors of Forest Biomass Carbon Storage in China: 1977-2013. - Forest 8: 263.

[54] Yang, M. F., Liu, Y. J., Liu, Y., Chen, H., Chen, F., Shen, S. H. (2009): Proteomic analysis of oil mobilization in seed germination and postgermination development of Jatropha curcas. - J Proteome Res. 8(3): 1441-1451.

[55] Zaynab, M., Kanwal, S., Furqan, M., Islam, W., Noman, A., Ali, G. M., Rehman, N., Zafar, S., Sughra, K. Jahanzeb, M. (2017): Proteomic approach to address low seed germination in Cyclobalnopsis gilva. - Biotechnol Lett 39: 1441. 